SHORT REPORT

\title{
Fetal growth predicts stress susceptibility independent of parental education in 161991 adolescent Swedish male conscripts
}

\author{
P M Nilsson, J-Å Nilsson, P-O Östergren, F Rasmussen
}

J Epidemiol Community Health 2004;58:571-573. doi: 10.1136/jech.2003.015495

$\mathrm{P}$ sychosocial stress could lead to a wide range of possible physiological reactions, due to both the total burden of stress as well as individual susceptibility. Two useful Swedish registers to investigate early life influences on stress susceptibility are the Swedish Medical Birth Register (MBR) and the Military Service Conscription Register (MSCR). In a previous study we showed a positive relation between fetal growth and psychological functioning (PF) including an assessment of stress susceptibility. ${ }^{1}$ However, in that study we did not adjust for family social class-nor did another related study. ${ }^{2}$ We have therefore now carried out such an analysis in an expanded cohort study, by adding parental educational level as a marker of family social class. The aim was to investigate independent associations between fetal growth and stress susceptibility in young men.

\section{METHODS}

We selected all Swedish men born in 1973-1979 and registered in the MBR $(\mathrm{n}=306$ 497). Birth characteristics recorded in MBR were linked to data on PF in the MSCR during 1990-1997. Excluded from the conscript test are men with severe physical or mental handicap $(n=43890)$. In all, 161991 young men had complete birth data and full data on PF using the same standardised methods. The study was approved by the ethical committee, University of Lund.

Recorded MBR variables were: birth weight (g), birth length $(\mathrm{cm})$, head circumference $(\mathrm{cm})$, gestational age (weeks), maternal age (years), and parity (n). We used data only from subjects with a birth weight between 1500-4499 grams, born at term ( $\geqslant$ week 37 ), and with head circumference $20-60 \mathrm{~cm}$, to avoid potential bias.

At conscription (MSCR) each young man undergoes a standard examination for $\mathrm{PF}$, which is based on a personal standardised interview with a military psychologist. ${ }^{1}$ This test (graded 1-9 scores; 9 highest) includes an evaluation of ability to cope with stress.

Data on parental education (years) were derived from the Population and Housing Census conducted by Statistics Sweden in 1970 and 1990.

\section{Statistics}

The three registers were linked by using unique personal 10 digit identification number. Birth weight was subdivided into centiles of aberration from expected birth weight adjusted for gestational week. We calculated the odds ratio (OR; 95\%CI) for the risk of being assessed for a low PF ( $\leqslant 4$ scores) in relation to impaired fetal growth, after adjustment for other birth characteristics and parental education, by use of the SAS program version 8 (Cary, NC, 1995). A p value less than 0.05 was considered significant.

\section{RESULTS}

Mean birth weight was 3576 (SD 436) grams after a mean of 39.9 (1.4) gestational weeks, as compared with a birth weight

Abbreviations: MBR, Medical Birth Register; MSCR, Military Service Conscription Register; PF, psychological functioning

Table 1 Psychological functioning (PF) scores in relation to categories of birth weight (registered birth weight in relation to expected birth weight) and paternal education (1970). Means (SD) and $95 \%$ confidence intervals (CI)

\begin{tabular}{|c|c|c|c|c|}
\hline Birth weight category (centiles) & Paternal educational category & Number & PF score mean (SD) & $95 \% \mathrm{Cl}$ \\
\hline \multirow[t]{4}{*}{ Lowest (1\%-5\%) } & lowest & 2041 & $4.61(1.81)$ & 4.53 to 4.69 \\
\hline & median-low & 3394 & $5.18(1.78)$ & 5.12 to 5.23 \\
\hline & median-high & 188 & $5.57(1.73)$ & 5.33 to 5.82 \\
\hline & highest & 372 & $5.54(1.75)$ & 5.36 to 5.72 \\
\hline \multirow[t]{4}{*}{ Second lowest (6\%-10\%) } & lowest & 2093 & $4.73(1.84)$ & 4.66 to 4.81 \\
\hline & median-low & 3348 & $5.22(1.77)$ & 5.16 to 5.28 \\
\hline & median-high & 212 & $5.39(1.87)$ & 5.13 to 5.64 \\
\hline & highest & 369 & $5.74(1.71)$ & 5.57 to 5.91 \\
\hline \multirow[t]{4}{*}{ Medium (1 1\%-90\%) } & lowest & 32176 & $4.94(1.76)$ & 4.92 to 4.96 \\
\hline & median-low & 56630 & $5.40(1.74)$ & 5.39 to 5.42 \\
\hline & median-high & 3919 & $5.77(1.71)$ & 5.72 to 5.83 \\
\hline & highest & 8109 & $5.78(1.76)$ & 5.74 to 5.82 \\
\hline \multirow[t]{4}{*}{ Second highest (91\%-95\%) } & lowest & 2177 & $4.98(1.80)$ & 4.91 to 5.06 \\
\hline & median-low & 3563 & $5.45(1.76)$ & 5.39 to 5.51 \\
\hline & median-high & 289 & $5.82(1.71)$ & 5.63 to 6.02 \\
\hline & highest & 596 & $5.93(1.76)$ & 5.79 to 6.07 \\
\hline \multirow[t]{4}{*}{ Highest (96\%-100\%) } & lowest & 2169 & 4.94 (1.79) & 4.86 to 5.01 \\
\hline & median-low & 3545 & $5.45(1.80)$ & 5.39 to 5.51 \\
\hline & median-high & 252 & $5.83(1.63)$ & 5.63 to 6.03 \\
\hline & highest & 598 & $5.81(1.77)$ & 5.67 to 5.96 \\
\hline
\end{tabular}




\section{Key points}

- Impaired fetal growth has been associated with various adult disease manifestations in epidemiological studies from different populations.

- Neuropsychological development could be negatively influenced by reduced fetal growth, one possible consequence being impaired cognitive function and increased stress susceptibility in young adult life.

- In 161991 Swedish male conscripts we found inverse associations between birth weight and psychological assessment scores including an evaluation of stress susceptibility, adjusted for other birth variables and parental educational level as a measure of childhood social class.

- Stress susceptibility in early adult life is more strongly associated with parental educational level than fetal growth, but both represent independent associations.

- Fetal growth thus seems to influence not only cognitive function, but also assessed susceptibility to stress-a factor of possible importance for adverse cardiovascular reactions with long term detrimental effects.

of 3448 (661) grams in the subjects excluded from conscript testing because of mental or physical handicap $(p<0.001)$. Mean value of the PF was 5.20 (1.80) scores. The PF score continuously increased with paternal educational level within each birth weight category (table 1) and with increasing paternal educational level. The odds ratio for receiving a low PF score $(\leqslant 4 ; 34 \%$ of all) was higher for subjects belonging to the two lowest birth weight categories, OR 1.27 ( 1.21 to 1.33 ) for $1-5$ th centile of birth weight in relation to expected birth weight for gestational age, and OR 1.25 ( 1.19 to 1.31 ) for $6-10$ th centile, as compared with the reference category (10-90th centile). This was still evident, OR 1.18 (1.11 to 1.25 ) and OR 1.17(1.10 to 1.24), respectively, after full adjustment for parental educational level and age, as well as other birth characteristics (maternal parity, head circumference, and birth length). Low paternal educational level was slightly more important, OR 1.28 (1.24 to 1.33 ), as a risk factor for obtaining a low PF score $(\leqslant 4)$ than birth weight alone in the fully adjusted statistical model (fig l).

\section{DISCUSSION}

This study showed an increased risk of stress susceptibility among growth retarded male military conscripts. This

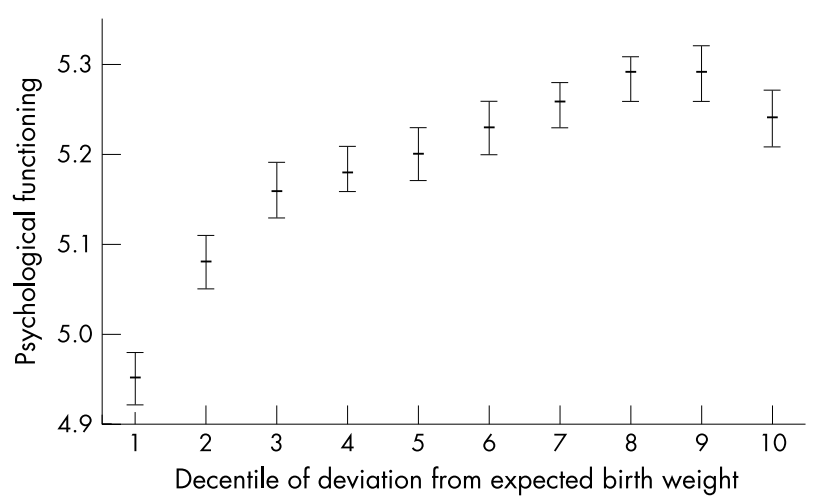

Figure 1 Psychological functioning score results, including an assessment of stress susceptibility, in relation to birth weight deviation from expected.

\section{Policy implications}

- Preventive efforts to ensure normal fetal growth and to strengthen family socioeconomic position in childhood may decrease the risk of boys growing up with increased stress susceptibility.

association was still evident after adjustment for parental educational level and other birth characteristics. This is in accordance with what has previously been reported in two similar Swedish studies, both however lacking adjustment for parental educational level. ${ }^{12}$ A positive association between size at birth and psychological function in women and men 42 years of age has recently been reported from a British population based cohort study, also after adjustment for childhood social class. ${ }^{3}$ Thus, both our studies consistently support the notion that fetal growth is important for PF in early adulthood.

We are aware of the fact that our findings are limited to young men and that the assessment of stress susceptibility by a military psychologist could potentially be influenced by day to day variation in mood, mental concentration, and cooperativeness of the conscripts. We also lack data on a number of subjects who were either not invited to the conscript test because of physical or mental abnormalities, or did not have a complete set of data. This potential bias is most probably diluting our findings, and not exaggerating them, as it would be suspected that an increased proportion of stress susceptible subjects belong to the excluded categories with handicaps. The correlations we obtained were weak, which is often the case in large scale epidemiological studies because of imprecision of measures, random variability, etc. Cognitive function may be a useful marker for long term health consequences as shown in other epidemiological studies. $^{45}$

In conclusion, impaired fetal growth is independently associated with increased stress susceptibility in young men.

\section{ACKNOWLEDGEMENTS}

We are grateful to Johan Lothigius, chief psychologist at the National Service Administration, Karl-stad, Sweden, for fruitful discussions and advice as regards the psychological test methods used at conscript examinations.

\section{CONTRIBUTORS}

PMN and FR developed the research questions, study design, and analytical strategies. PMN drafted the paper and all authors contributed to the final version. FR created the database and JÅN conducted the statistical analyses. PMN is the guarantor.

\section{Authors' affiliations \\ P M Nilsson, J-Å Nilsson, Department of Medicine, University Hospital, Malmö, Sweden \\ P-O Östergren, Department of Community Medicine, University Hospital, Malmo, Sweden \\ F Rasmussen, Department of Public Health Sciences, Karolinska Institute, Stockholm, Sweden \\ Funding: PMN was supported by grants from the Swedish Medical Association. \\ Competing interests: none declared.}

Correspondence to: Dr P Nilsson, Department of Medicine, University Hospital, S-205 02 Malmö, Sweden; Peter.Nilsson@medforsk.mas.lu.se

Accepted for publication 11 November 2003 


\section{REFERENCES}

1 Nilsson P, Nyberg P, Östergren P-O. Susceptibility to a psychological stress test in young males is associated with low birth weight. Int J Epidemiol $2001 ; 30: 75-80$.

2 Lundgren EM, Cnattingius S, Jonsson B, et al. Intellectual and psychological performance in males born small for gestational age with and without catchup growth. Pediatr Res 2001;50:91-6.
3 Cheung YB, Khoo KS, Karlberg J, et al. Association between psychological symptoms in adults and growth in early life: longitudinal follow up study. BMJ 2002;325:749-53.

4 Jiang GX, Rasmussen F, Wasserman D. Short stature and poor psychological performance: risk factors for attempted suicide among Swedish male conscripts. Acta Psychiatr Scand 1999:100:433-40.

5 Breslau N. Psychiatric sequelae of low birth weight. Epidemiol Rev 1995; 17:96-106

\section{THE JECH GALLERY}

Influential women in occupational health

doi: $10.1136 /$ jech.2003.008821 Andrea Kidd Taylor-Ensuring safety for labour

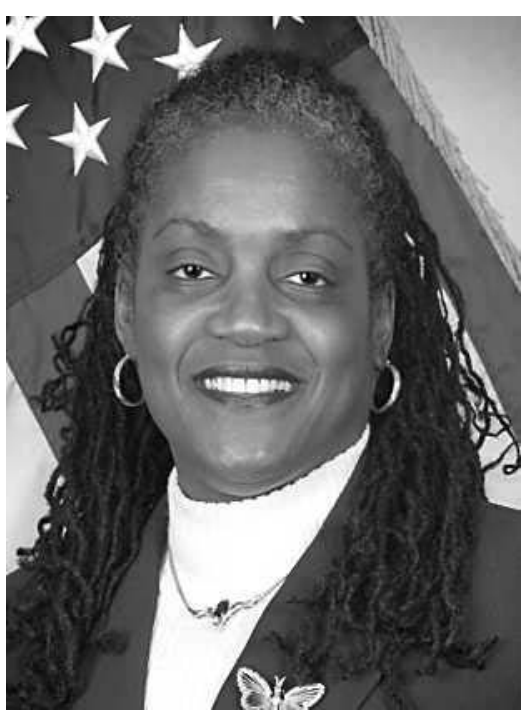

January 1955-, Country of birth: USA.

ndrea Kidd Taylor, DrPH, MSPH, embodies the personification of the American Dream.

A Born of a middle class Southern family in the late 20th century, she was one of the firs African-American children to attend, and thereby, de-segregate an all white school

Reflecting her family's strong background in organised labour, Taylor worked as an industrial hygienist and occupational health policy consultant for the International Union, United Automobile, Aerospace, and Agricultural Implement Workers of America (UAW), playing a seminal part in many Right-to-Know programmes throughout the USA.

"To achieve gains in health, public policies must be implemented that overcome discrimination and reduce exploitation of labor, thereby promoting socioeconomic equity and improved health status for all people."

Unafraid to tackle major health policy questions, she served on the Presidential Advisory Committee on Gulf War Veterans' Illnesses, and has represented organised labour on the National Advisory Committee on Occupational Safety and Health. In 1998, Taylor was appointed to the US Chemical Safety and Hazard Investigation Board (CSB), empowered to investigate major chemical accidents that involve deaths or serious harm to workers and the public.

\footnotetext{
Ilise L Feitshans

Adjunct Faculty, Cornell University, School of Industrial and Labor Relations, Albany, NY, USA Deborah F Salerno Clinical Communications Scientist, Pfizer Global Research and Development-Michigan Laboratories, Ann Arbor, MI, USA

Correspondence to: Deborah F Salerno, 2800 Plymouth Road, Ann Arbor, MI 48105, USA; deborah.salerno@pfizer.com
} 